\title{
Late onset renal failure from angiotensin blockade (LORFFAB) and the syndrome of rapid onset end- stage renal disease (SORO-ESRD) revisited - Two case reports from Mayo Clinic Health System, Northwestern Wisconsin, USA; a review paper
}

\author{
Macaulay Amechi Chukwukadibia Onuigbo ${ }^{1,2^{*}}$, Eileen Samuel ${ }^{2}$, Nneoma Agbasi $^{3}$ \\ ${ }^{1}$ Mayo Clinic College of Medicine, Rochester, MN, USA \\ ${ }^{2}$ Department of Nephrology, Mayo Clinic Health System, Eau Claire, WI, USA \\ ${ }^{3}$ North East London NHS Foundation Trust, UK
}

\section{A R T I C L E IN F O}

Article Type:

Review

\section{Article History:}

Received: 9 August 2017

Accepted: 20 November 2017

Published online: 2 January 2018

\section{Keywords:}

Acute kidney injury, Angiotensin blockade, Angiotensin converting enzyme inhibitor, Angiotensin receptor blocker, Chronic kidney disease, Late onset renal failure from angiotensin blockade

\begin{abstract}
A B S T R A C T
In 2005, we described for the first time, the syndrome of late onset renal failure from angiotensin blockade (LORFFAB). This is accelerated loss of kidney function in patients on a priori stable doses of an angiotensin converting enzyme inhibitor and/or an angiotensin receptor blocker (ARB), for more than 3 months, with this acute kidney injury (AKI) occurring in the absence of any identifiable known precipitating factors. Moreover, in 2010, we described the syndrome of rapid onset end-stage renal disease (SORO-ESRD). This is acute yet irreversible renal failure following medical illness or surgical procedures, again sometimes in association with concurrent angiotensin blockade. In this article, we describe two representative case reports, one case for LORFFAB and another case for SORO-ESRD and subsequently discuss the implications of LORFFAB and SORO-ESRD in current nephrology practice paradigms. Whereas we support the consensus that angiotensin blockade, for now, remains the mainstay of renoprotection, we however must draw attention to the potential for nephrotoxicity from angiotensin blockade under certain clinical scenarios including the ones described here and more. The association of LORFFAB and SORO-ESRD demands further investigation.
\end{abstract}

Implication for health policy/practice/research/medical education:

In 2005, we had described for the first time, the syndrome of late onset renal failure from angiotensin blockade (LORFFAB), represented by the observed accelerated loss of kidney function in patients on a priori stable doses of an angiotensin converting enzyme inhibitor and/or an angiotensin receptor blocker, for more than three months, with this acute kidney injury (AKI) occurring despite the absence of any identifiable known precipitating factors. Moreover, in 2010, we had described the syndrome of rapid onset end-stage renal disease (SORO-ESRD), represented by acute yet irreversible renal failure following medical illness or surgical procedures, again sometimes in association with concurrent angiotensin blockade. In this article, we describe two representative case reports, one each of both syndromes, and discuss the implications of LORFFAB and SORO-ESRD in current nephrology practice paradigms.

Please cite this paper as: Onuigbo M, Samuel E, Agbasi N. Late onset renal failure from angiotensin blockade (LORFFAB) and the syndrome of rapid onset end-stage renal disease (SORO-ESRD) revisited - Two case reports from Mayo Clinic Health System, Northwestern Wisconsin, USA; a review paper. J Renal Inj Prev. 2018;7(2):58-63. DOI: 10.15171/jrip.2018.15.

\section{Introduction}

In 2005, from the Renal Unit of Mayo Clinic Health System, in Northwestern Wisconsin, we had described for the first time, the syndrome of late onset renal failure from angiotensin blockade (LORFFAB) (1). The classic diagnosis of this syndrome of LORFFAB was predicated on a patient satisfying the following criteria (1-6).

1. The presence of $\geq 25 \%$ increase in baseline serum 
creatinine, while on concomitant angiotensin converting enzyme inhibitor (ACEI) and/or angiotensin receptor blocker (ARB) therapy.

2. The dose(s) of angiotensin inhibition must have been the same for at least three months prior to presentation. 3. All the previously described so-called traditional precipitating risk factors for renal failure associated with angiotensin inhibition including hypotension, nonsteroidal anti-inflammatory drugs (NSAIDs) use, dehydration, iodinated contrast exposure and heart failure exacerbation must be absent.

4. The patient must demonstrate angiographic evidence of normal renal arteries.

Furthermore, in 2010, we had described the syndrome of rapid onset end-stage renal disease (SORO-ESRD), represented by acute yet irreversible renal failure, requiring the institution of renal replacement therapy (RRT), following medical events or surgical procedures, again often in association with concurrent angiotensin blockade (7). Our working definition of SORO-ESRD is any patient with an a priori stable estimated glomerular filtration rate (eGFR) of $\geq 30 \mathrm{~mL} / \mathrm{min} / 1.73 \mathrm{~m}^{2}$, on or before the $90 \mathrm{th}$ day preceding initiation of first RRT for renal failure, who develops renal failure from an acute kidney injury (AKI) event and who thereafter had remained permanently on RRT for over 90 days and beyond without renal recovery (7-10). Quite often, the interval between the precipitating AKI event and the need for RRT is less than 2 weeks, and commonly is only in days following cardiothoracic procedures (7-10).

Following our reports on the syndrome of LORFFAB and having raised concerns regarding the unrecognized potential nephrotoxicity associated with angiotensin blockade, similar experiences have been observed in a few other centers around the world, including the work of El Nahas and his group from the Sheffield Kidney Institute, Sheffield, in the United Kingdom, implicating angiotensin blockade in the causation of clinically significant and sometimes unrecognized renal failure (11-13).

In this article, we describe two representative case reports, one each of both syndromes, and discuss the implications of LORFFAB and SORO-ESRD in current nephrology practice paradigms.

\section{Case I - LORFFAB}

In April 2016, our nephrology outpatient service was consulted regarding an active 74-year old hypertensive Caucasian male patient, an ex-smoker, for worsening renal failure. Other past medical history included coronary artery stents with angioplasties in 1986 and 1997, impaired glucose tolerance, gout, obesity and abdominal aortic aneurysm repair in 2002, prior history of recovered acute renal failure secondary to NSAIDs, and stage III chronic kidney disease (CKD) with prior baseline serum creatinine of about $1.5 \mathrm{mg} / \mathrm{dL}$ in 2014 and 2015 - serum creatinine was $1.48 \mathrm{mg} / \mathrm{dL}$ in October 2014 and $1.45 \mathrm{mg} /$
dL in October 2015. Outpatient medications in April 2016 included lisinopril $20 \mathrm{mg}$ daily, baby aspirin $81 \mathrm{mg}$ daily, atenolol $50 \mathrm{mg}$ two times daily, atorvastatin $40 \mathrm{mg}$ daily, omeprazole $20 \mathrm{mg}$ daily, as needed acetaminophen and sublingual nitroglycerin. Records show that the lisinopril was started in September 2015.

$\mathrm{He}$ had seen his internist for a scheduled annual examination and was otherwise asymptomatic. Heart rate 68 , blood pressure $112 / 72 \mathrm{~mm} \mathrm{Hg}$, weight is $89.8 \mathrm{~kg}$. No edema was evident, and physical examination overall was unremarkable. Laboratory testing revealed significantly elevated serum creatinine at $3.18 \mathrm{mg} / \mathrm{dL}$, with associated hyperkalemia of $5.8 \mathrm{mmol} / \mathrm{L}$ (Figures 1 and 2). The diagnosis was suspected lisinopril nephrotoxicity and he was sent to the emergency room where he received $500 \mathrm{cc}$ intravenous bolus of normal saline, followed by a single intravenous dose of furosemide and lisinopril was promptly discontinued. He was then followed up in the Nephrology office the following week.

Just the next day, serum creatinine had decreased to 2.48 $\mathrm{mg} / \mathrm{dL}$, and was down to $2.21 \mathrm{mg} / \mathrm{dL}$ twelve days later (Figure 3). It was $1.50 \mathrm{mg} / \mathrm{dL}$ about three months later and has remained stable since then. Serum potassium similarly had normalized twelve days later. The most recent serum creatinine from April 2017 is $1.53 \mathrm{mg} / \mathrm{dL}$ (Figure 4).

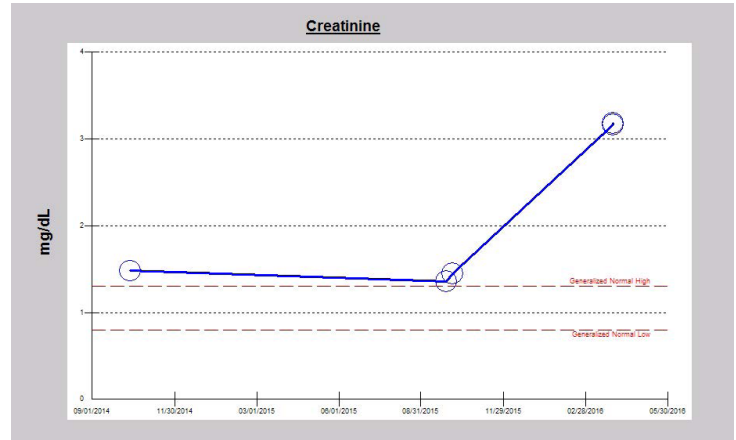

Figure 1. Serum creatinine trajectory, September 2014 through April 2016 showing accelerated loss of kidney function with a higher serum creatinine of $3.18 \mathrm{mg} / \mathrm{dL}$ during an annual review in April, 2016.

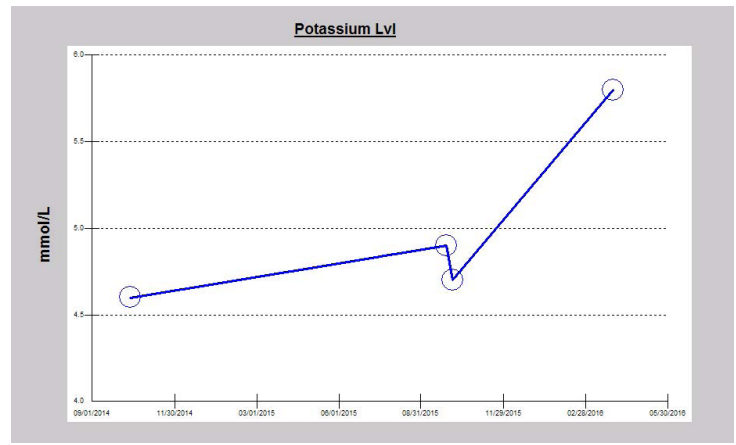

Figure 2. Serum potassium trajectory, September 2014 through April 2016 showing hyperkalemia of $5.8 \mathrm{mmol} / \mathrm{L}$ associated with acute kidney injury during an annual review in April, $2016 .$. 
Currently in April, 2017, he continues to maintain a stable serum creatinine of $1.53 \mathrm{mg} / \mathrm{dL}(\mathrm{eGFR}=45 \mathrm{~mL} /$ $\mathrm{min} / 1.73 \mathrm{~m}^{2} \mathrm{BSA}$ ), nearly a year later, and his current antihypertensive agents are amlodipine $5 \mathrm{mg}$ daily, metoprolol tartrate $37.5 \mathrm{mg}$ daily and tamsulosin $0.4 \mathrm{mg}$ daily.

\section{Case II - SORO-ESRD}

In late February 2012, a 73-year old morbidly obese diabetic hypertensive Caucasian male patient, with stable stage III CKD, baseline serum creatinine ranging from 1.5-1.9 mg/dL (2005-2012) was evaluated for one week's history of worsening exertional dyspnea (Figure 5). He was on amlodipine $10 \mathrm{mg}$ once daily, atenolol-chlorthalidone $100 / 25$, one tablet daily, atorvastatin $80 \mathrm{mg}$ daily, insulin isophane $\mathrm{N} 28$ units daily before breakfast and 18 units at bedtime, with regular insulin, 9 units in the morning and 7 units at $4 \mathrm{PM}$. for glucose levels greater than $100 \mathrm{mg} / \mathrm{dL}$, lisinopril $40 \mathrm{mg}$ daily and multivitamin with minerals, one tablet daily.

Blood pressure control in February 2012 was adequate, temperature $36.6^{\circ} \mathrm{C}$, pulse was 57 per minute, respiratory rate 16 per minute, blood pressure 147/76 mm Hg, saturating at $93 \%$ on $3 \mathrm{~L} / \mathrm{min}$ nasal cannula oxygen. $\mathrm{HgAlc}$ was 7\%, serum creatinine was $1.72 \mathrm{mg} / \mathrm{dL}$ (eGFR

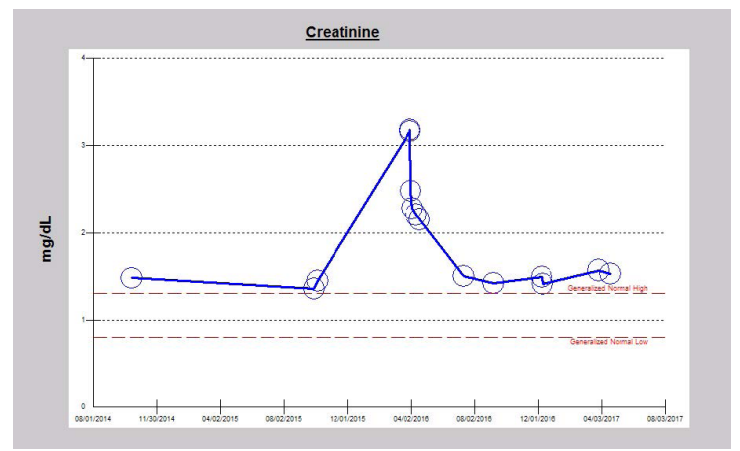

Figure 3. Improved serum creatinine of within 2 weeks of discontinuation of lisinopril in April, 2016 and subsequent stabilization, a year later in April 2017.

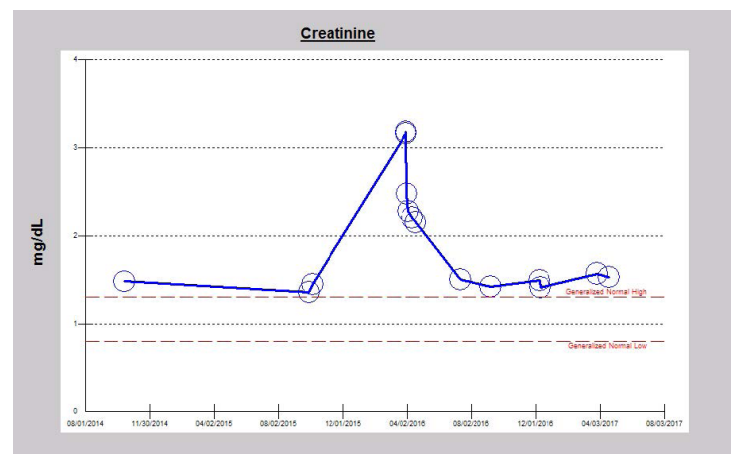

Figure 4. Serum creatinine trajectory, September 2014 through April 2017 showing acute kidney injury in April 2016 while on lisinopril and subsequent recovery of kidney function following the withdrawal of lisinopril.

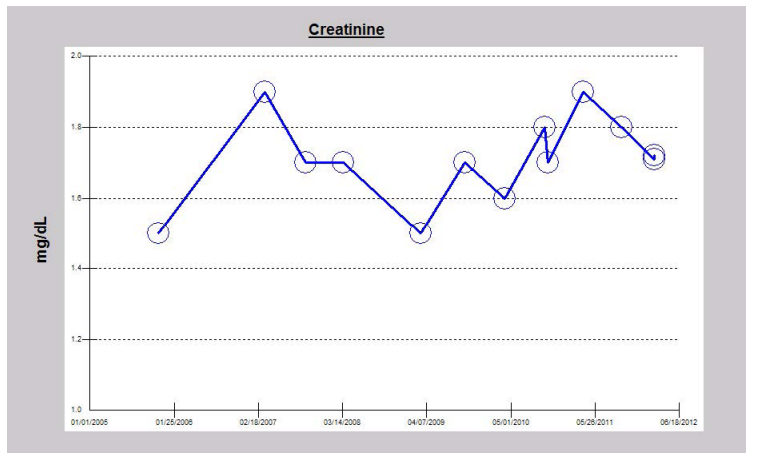

Figure 5. Stable CKD III with serum creatinine trajectory, November 2005 through February 2012, 1.5-1.9 mg/dL.

of $\left.39 \mathrm{~mL} / \mathrm{min} / 1.73 \mathrm{~m}^{2} \mathrm{BSA}\right)$. An echocardiogram revealed moderate left ventricular hypertrophy, elevated right atrial filling pressure $(>15 \mathrm{~mm} \mathrm{Hg})$, mild pulmonary hypertension (PASP 40-49 $\mathrm{mm} \mathrm{Hg}$ ) and critical/severe aortic stenosis. Left ventricular ejection fraction was $50 \%$ without any identifiable wall motion abnormalities. He underwent coronary angiography on 2-28-12 and there was no obstructive coronary artery disease.

On March 2, 2012, the patient underwent minimally invasive aortic valve replacement (AVR) with a $25 \mathrm{~mm}$ St. Jude Epic Stented Tissue Valve via cardiopulmonary bypass (CPB) - Bypass time was 150 minutes, CrossClamp time was 101 minutes and total operating room time under anesthesia was 7 hours (745 AM-1445 PM). By the end of the first post-operative day, the patient required the initiation of 24-hour continuous venovenous hemodialysis (CVVHD) with ultrafiltration for worsening AKI (Figure 6), oligo-anuria and progressively increasing volume overload.

Emergent hemodialysis was started the very next day following the surgery due to rising creatinine (Figure 6), oligo-anuria and worsening volume overload. His hemodialysis regimen was 24 hours nonstop CVVHD with slow ultrafiltration for five days, and then was switched to shorter 4-6 hours daily hemodialysis treatments and by the second week was de-escalated to three times weekly hemodialysis. He has since remained on in-center outpatient three times a week hemodialysis at the Mayo Clinic Dialysis System Unit in Eau Claire, WI, USA for over 5 years. His current serum creatinine as at May 5, 2017 is $8.66 \mathrm{mg} / \mathrm{dL}$ and he remains anuric (Figure 7).

\section{Discussion}

The first case presented above demonstrated the potential for angiotensin blockade to cause nephrotoxicity, consistent with the diagnosis of LORFFAB.

Since our first report of the syndrome of LORFFAB in 2005 , over the last ten or more years, we have variously described the features of this syndrome in various journal publications, book chapters and editorial pieces as well as in professional academic intellectual forums 


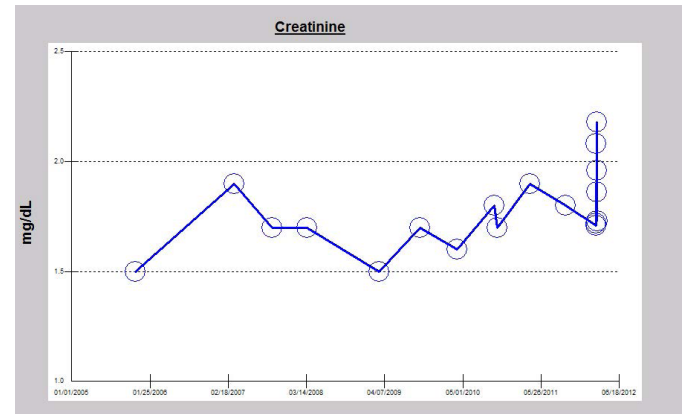

Figure 6. Trajectory of serum creatinine demonstrating acute rise 1-2 days following the minimally invasive aortic valve replacement procedure associated with oliguria and worsening volume overload that triggered the initiation of hemodialysis with ultrafiltration.

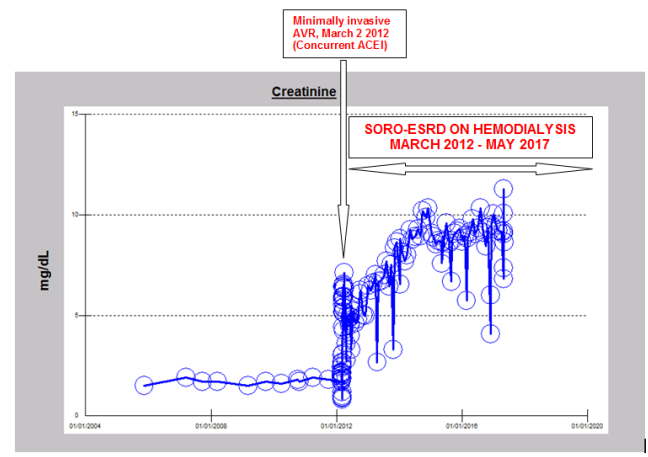

Figure 7. Serum creatinine trajectory, November 2005 May 2017, showing acute yet irreversible renal failure or the syndrome of rapid onset ESRD since the valve replacement procedure in March 2012.

and presentations (1-6). It was indeed our work at the Mayo Clinic Health System in Northwestern Wisconsin that spurred the work of El Nahas and his group from the Sheffield Kidney Institute, Sheffield in the United Kingdom who concluded in 2010 that discontinuation of ACEI/ARB had undoubtedly delayed the onset of RRT in the majority of those studied and that this observation might justify a rethink of our approach to the inhibition of the renin-angiotensin-aldosterone system (RAAS) in patients with advanced CKD who are nearing the start of RRT $(11,12)$. Some other investigators around the world have shown similar reports raising concerns about the potential nephrotoxicity of angiotensin blockade especially in the elderly (>65-year old) with more advanced CKD (13-15). As a result of these legitimate concerns, we now have a randomized controlled trial to determine whether the pre-emptive withdrawal of ACEI/ARB in patients with advanced $\mathrm{CKD}$ would result in improved cardiorenal outcomes - the ongoing STOP ACEi Trial $(16,17)$.

The second case report presented above demonstrated the syndrome of rapid onset ESRD, or SORO-ESRD, that is to say, acute yet irreversible renal failure requiring permanent RRT including kidney transplantation where applicable (7-10). Several other large studies of the trajectories of renal failure to ESRD have confirmed our observations (18-20). In the more recent nephrology literature, 2011-2012, we have further identified three corroborating new reports that have further substantiated our recent descriptions of the phenomenon of SOROESRD (18-20). These three reports have each additionally demonstrated that a significant proportion of the incident adult ESRD population in both the United States and Canada, respectively, satisfy the diagnostic criteria for our newly described syndrome of rapid onset end stage renal disease (18-20).

\section{Conclusion LORFFAB and SORO-ESRD}

In conclusion, we acknowledge and support the consensus that angiotensin blockade, for now, remains the mainstay of renoprotection in general nephrology care. We however must draw attention to the potential for nephrotoxicity from angiotensin blockade in several clinical scenarios including the ones described here and more. The association of LORFFAB and SORO-ESRD demands further investigation. In our small 100-patient experience in northwestern Wisconsin, we were able to demonstrate an association of angiotensin blockade with SORO-ESRD (7-10). A just published report from Saudi Arabia revealed an association of continued angiotensin blockade with hospital-acquired AKI (15). Besides, we had demonstrated in a 13-year retrospective analysis of 1461 ESRD patient managed at Mayo Clinic, Rochester, 2001-2013, an incidence rate of SORO-ESRD of $10 \%$ but we were not able to show any association between SOROESRD and concurrent angiotensin blockade (21).

Finally, we would call for caution in the use of angiotensin blockade in older ( $>65$-year old) patients with advanced CKD. Serum creatinine must be monitored, closely and indefinitely. Notably, a new report from the United Kingdom showed that $10 \%$ of patients on ACEI/ARB had neither baseline nor follow-up monitoring of creatinine within 12 months before and 2 months after initiation of an ACEI/ARB, 28\% had monitoring only at baseline, 15\% only at follow-up, and $47 \%$ both at baseline and followup (22). Providers need to adhere more to the guidelines for safe use of ACE inhibitors and angiotensin receptor blockers (23).

\section{POST-SCRIPT}

One recurring theme in this presentation is the demonstration that the superb utility and value of the close and meticulous monitoring of individual-patient serum creatinine trajectories in the real-time management of AKI in hospitalized patients cannot be over-emphasized (24-26). The conclusion from our recent investigation of this paradigm of nephrology care was that the analysis of serum creatinine trajectories, both in real time and retrospectively, indeed provides supplementary superior diagnostic and prognostic insights in the management of the general nephrology patient. 
Authors' contribution

MACO: Conception, design, acquisition of data, data analysis, interpretation of data, literature review, drafting the article and final approval of manuscript. ES: Acquisition of data, literature review and final approval of manuscript. NA: Critical revising for important intellectual content, design, and final approval of manuscript.

\section{Conflicts of interest}

The authors report no conflicts of interest. The authors alone are responsible for the content and writing of the article.

\section{Ethical considerations}

Ethical issues (including plagiarism, data fabrication, double publication) have been completely observed by the authors. The patients had given their informed consent regarding these case reports. This paper is a review article along with case discussion.

\section{Funding/Support}

None.

\section{References}

1. Onuigbo MA, Onuigbo NT. Late onset renal failure from angiotensin blockade (LORFFAB): a prospective thirtymonth Mayo Health System clinic experience. Med Sci Monit. 2005;11:462-9.

2. Onuigbo MA, Onuigbo NT. Use of ultrahigh RAAS blockade: implications for exacerbation of renal failure. Kidney Int. 2006;69:194-5. doi: 10.1038/sj.ki.5000068

3. Onuigbo MA, Onuigbo NT. Late-onset renal failure from RAAS blockade. Kidney Int. 2006;70:1378-9. doi:10.1038/ sj.ki.5001648.

4. Onuigbo MA, Onuigbo NT. Late-onset renal failure from angiotensin blockade (LORFFAB) in 100 CKD patients. Int Urol Nephrol. 2008;40:233-9. doi: 10.1007/s11255-0079299-2.

5. Onuigbo MA, Onuigbo NT. Late onset azotemia from RAAS blockade in CKD patients with normal renal arteries and no precipitating risk factors. Ren Fail. 2008;30:73-80. doi: $10.1080 / 08860220701742161$.

6. Onuigbo MA, Achebe NJ. Late Onset Renal Failure From Angiotensin Blockade (LORFFAB) - The Results of a Mayo Clinic Health System Angiotensin Inhibition Withdrawal Study: A Clarion Call For More Preventative Nephrology, Also Called Renoprevention. In: Macaulay Amechi Chuka Onuigbo, ed. ACE inhibitors: medical uses, mechanisms of action, potential adverse effects and related topics. NOVA Publishers; 2013:75-90.

7. Onuigbo MA. Syndrome of rapid-onset end-stage renal disease: a new unrecognized pattern of CKD progression to ESRD. Ren Fail. 2010;32:954-958. doi: 10.3109/0886022X.2010.502608.

8. Onuigbo M, Onuigbo N, eds. Chronic Kidney Disease and RAAS Blockade: A New View of Renoprotection. London, England: Lambert Academic Publishing; 2011.

9. Onuigbo MA, Onuigbo NT. The Syndrome of Rapid Onset End-Stage Renal Disease (SOROESRD) - A New Mayo Clinic Dialysis Services Experience, January 2010-February
2011. In: Di Iorio B, Heidland A, Onuigb Mo, Ronco C, eds. Hemodialysis: How, When and Why. NOVA Science Publishers; 2012:443-85.

10. Onuigbo MA, Achebe NJ, Musso CG. The syndrome of rapid onset ESRD in the last 100 consecutive incident Northwestern Wisconsin Mayo Clinic chronic hemodialysis patients, 2010-2011: Results of the analysis of individual patient-level serum creatinine trajectories to ESRD - Can there be a link with angiotensin inhibition and renal senescence in older CKD patients? In: Onuigbo MAC, ed. ACE inhibitors: medical uses, mechanisms of action, potential adverse effects and related topics. NOVA Publishers; 2013:109-25.

11. Ahmed AK, Kamath NS, El Kossi M, El Nahas AM. The impact of stopping inhibitors of the renin-angiotensin system in patients with advanced chronic kidney disease. Nephrol Dial Transplant. 2010;25:3977-82. doi: 10.1093/ ndt/gfp511.

12. Gonçalves AR, Khwaja A, Ahmed AK, El Kossi M, El Nahas M. Stopping renin-angiotensin system inhibitors in chronic kidney disease: predictors of response. Nephron Clin Pract. 2011;119:348-54.

13. Oh YJ, Kim SM, Shin BC, Kim HL, Chung JH, Kim AJ. The impact of renin-angiotensin system blockade on renal outcomes and mortality in pre-dialysis patients with advanced chronic kidney disease. PLoS One. 2017;12:e0170874. doi: 10.1371/journal.pone.0170874.

14. Schmidt M, Mansfield KE, Bhaskaran K, Nitsch D, Sørensen HT, Smeeth L, et al. Serum creatinine elevation after reninangiotensin system blockade and long term cardiorenal risks: cohort study. BMJ. 2017;356:j791. doi: 10.1136/bmj. j791.

15. Alabdan N, Gosmanova EO, Tran NQ, Oliphant CS, Pan H, Broyles JE, et al. Acute kidney injury in patients continued on renin-angiotensin system blockers during hospitalization. Am J Med Sci. 2017;353:172-7. doi: 10.1016/j.amjms.

16. Bhandari S, Ives N, Brettell EA, Valente M, Cockwell P, Topham PS, et al. Multicentre randomized controlled trial of angiotensin-converting enzyme inhibitor/angiotensin receptor blocker withdrawal in advanced renal disease: the STOP-ACEi trial.Nephrol Dial Transplant. 2016;31:255-61. doi: 10.1093/ndt/gfv346.

17. Onuigbo MA. The STOP-ACEi Trial - Apt timing for this long awaited randomised controlled trial - Validation of the syndrome of late-onset renal failure from angiotensin blockade (LORFFAB)? Int J Clin Pract. 2017;71. doi: 10.1111/ijcp.12916.

18. Lee $\mathrm{P}$, Johansen K, Hsu CY. End-stage renal disease preceded by rapid declines in kidney function: a case series. BMC Nephrol. 2011;12:5.

19. O'Hare AM, Batten A, Burrows NR, Pavkov ME, Taylor L, et al. Trajectories of kidney function decline in the 2 years before initiation of long-term dialysis. Am J Kidney Dis. 2012;59:513-22.

20. Siddiqui NF, Coca SG, Devereaux PJ, Jain AK, Li L, et al. Secular trends in acute dialysis after elective major surgery -- 1995 to 2009. CMAJ. 2012;184:1237-45. doi: 10.1503/ cmaj.110895.

21. Onuigbo M, Agbasi N. Syndrome of rapid onset ESRD accounted for high hemodialysis catheter use--results of a 13-year Mayo Clinic incident hemodialysis study. Ren Fail. 2015;37:1486-91. doi: 10.3109/0886022X.2015.1088336. 
22. Schmidt M, Mansfield KE, Bhaskaran K, et al. Adherence to guidelines for creatinine and potassium monitoring and discontinuation following renin-angiotensin system blockade: a UK general practice-based cohort study. BMJ Open. 2017;7:e012818. doi:10.1136/bmjopen-2016012818

23. Onuigbo MA, Agbasi NC. A call for more adherence to guidelines for creatinine and potassium monitoring and discontinuation following renin-angiotensin system blockade : a UK general practice-based cohort study. BMJ Open. 2017;7:e012818corr1. doi: 10.1136/bmjopen-2016012818 corr 1 .

24. Onuigbo MA, Agbasi N. Diabetic nephropathy and CKD Analysis of individual patient serum creatinine trajectories:
A forgotten diagnostic methodology for diabetic CKD prognostication and prediction. J Clin Med. 2015;4:134868. doi: $10.3390 / \mathrm{jcm} 4071348$.

25. Onuigbo M, Agbasi N, Oguejiofor O, Okocha E, Aneke C, Odenigbo C. Serum Creatinine Trajectories in Kidney Disease. In: Patel VB, Preedy VR, eds. Biomarkers in Disease: Methods, Discoveries and Applications. Biomarkers in Kidney Disease. Dordrecht: Springer; 2016:139-170.

26. Onuigbo MA, Samuel E, Agbasi N. Hospital-acquired nephrotoxic exposures in the precipitation of acute kidney injury - A case series analysis and a call for more preventative nephrology practices. J Nephropharmacol. 2017;6:90-7. doi: 10.15171/npj.2017.11.

Copyright $\odot 2018$ The Author(s); Published by Nickan Research Institute. This is an open-access article distributed under the terms of the Creative Commons Attribution License (http://creativecommons.org/licenses/by/4.0), which permits unrestricted use, distribution, and reproduction in any medium, provided the original work is properly cited. 